\title{
IT Governance Framework and the Strategic Management System: the case of Universitat Jaume I
}

\author{
Vicente Andreu Navarro ${ }^{1}$, José Gumbau ${ }^{2}$, Paúl Santapau ${ }^{3}$ and Andrés Marzal ${ }^{4}$ \\ ${ }^{1}$ Senior Technology Innovation Specialist, andreuv@uji.es. \\ ${ }^{2}$ Head of Office for Planning and Technology Forecast, gumbau@sg.uji.es. \\ ${ }^{3}$ Technology Innovation Specialist, santapau@uji.es. \\ ${ }^{4}$ Manager, Universitat Jaume I, Spain, Andres.Marzal@uji.es. \\ Keywords \\ IT Governance, ISO 38500, GTU4U.
}

\section{ABSTRACT}

IT governance is the ability of the organization to guide the design and implementation processes of IT. The liability for this guidance pertains to the Governing Bodies of the institution that should use it as a means of guaranteeing the alignment of IT initiatives with the general business strategy (Van Grembergen, 2004).

\section{IT GOVERNANCE SYSTEM MODEL FOR UNIVERSITIES}

Spanish universities, like any other organisation, have the need to establish IT governance systems with the aim of improving the organization's performance. One of the most recent initiatives of the Rectors Conference (CRUE) has been to promote a model for IT governance and a set of guidelines for its development in Spanish universities. CRUE proposes a model (GTI4U) that is based on the international standard ISO/IEC 38500:2008. This standard covers the management and evaluation of IT usage plans that supports the organization and the monitoring of this usage to achieve what is stated in the plans. It establishes the fundamentals for good practices in IT governance, from a high management perspective, and incorporates a very detailed analysis procedure that evaluates the different aspects of IT in the organization. It also uses the maturity model concept that is incorporated in the ISO 38500 standard.

Universitat Jaume I from Castellón leads the workgroup of Analysis, Planning and IT Governance of the CRUE-TIC (IT sectorial committee of the Rectors Conference). This workgroup has developed, in close cooperation with a research team from different Spanish academic institutions, the GTI4U model and has started, beginning 2010, the project to deploy IT governance instruments in Spanish universities.

In this abstract the process that each of the universities has followed to link this model to its strategic management system is described. The process is part of what has been defined as Technological Framework for IT Governance, a management model for the incorporation of IT to business processes. The model proposed facilitates decision-making related to IT and incorporates some decision procedures to the agenda of the management bodies of each institution, enhancing, thus, the alignment of IT strategies with business strategies.

On an annual basis, following the GTI4U model, a committee integrated by people from different areas of each university (and if required, with the aid of external advisors) analyses good practices and evaluates the maturity of the university regarding different perspectives defined in ISO 38500 standard (see figure 1): Liability, Strategy, Acquisition, Performance, Compliance and Human Behaviour. 


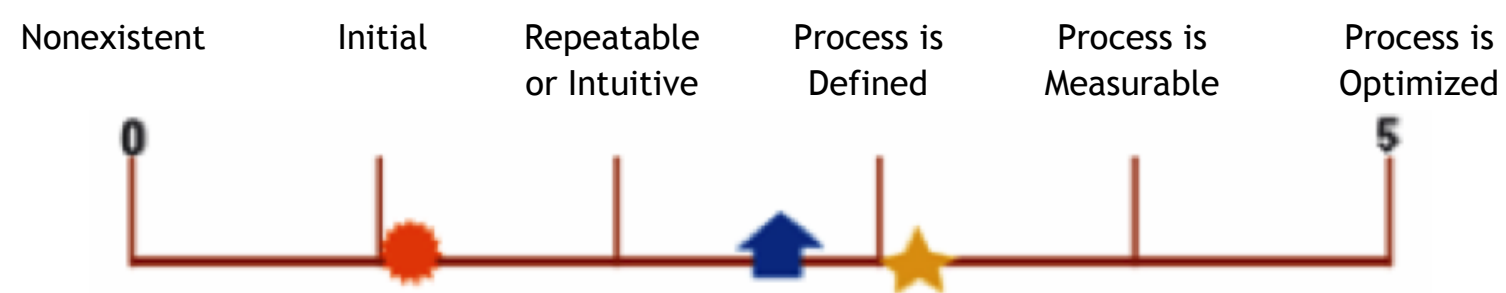

Current university status

SUE $^{1}$ mean value

Short-term ${ }^{2}$ university objective
0. The university does not know the principle and is not concerned about needing it.

1. Principle is established but the processes are disorganised and ad-hoc.

2. Principle is immature, processes follow an irregular pattern.

3. Principle begins to become mature, processes are documented and have been distributed.

4. Principle is quite mature, the processes are being measured and monitorised.

5. Principle has reached an optimal level, based on good practices.

Figure 1. Analysis reference framework

The scales of the maturity model and the iconographic model help the people in charge of IT to explain to the University Management Committee in which areas deficiencies have been identified and contributes to clarify the decision making process for establishing improvement objectives where required.

In the mid-term3, to have a common model and a common metric system will allow the Spanish Universities to compare to each other and to perform benchmarking that will benefit the whole Higher Education sector in Spain.

\section{REFERENCES}

Van Grembergen, W. Haes, S. (2008). Implementing Information Technology Governance. Models, Practices and Cases. IGI Publishing.

Weill, P. y Ross, J.W. (2004). IT Governance: How Top Performers Manage IT Decision Rights for Superior Results. Harvard Business School Press.

Fernández, A. Llorens, F. De Andrés Rivero, J. (2011). kTI, a self-assessment IT governance system. Retrieved May 17, 2013, from: http://www.eunis.ie/papers/kTI_AntonioFernandez_Paper.pdf

\footnotetext{
${ }^{1}$ SUE stands for Sistema Universitario Español, Spanish Higher Education System.

${ }^{2}$ Annual.

${ }^{3}$ A few years.
} 


\section{AUTHORS' BIOGRAPHIES}

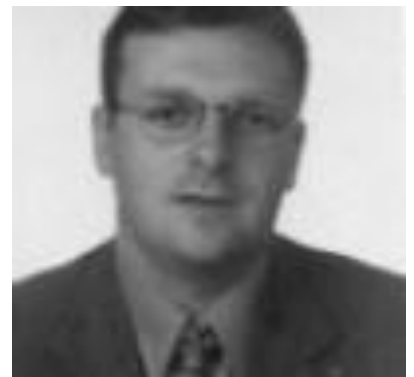

Vicent Andreu works as a Senior Technology Innovation Specialist at the Office for Planning and Technology Forecast of the Universitat Jaume I. He graduated in computer science from Universidad Politécnica de Valencia and obtained MSc in Knowledge and Information Society at Universitat Oberta de Catalunya. He was the coordinator of the Student Mobility Pilot in STORK project and currently he is working on Security Management, Data Protection and coordinates the eLearning and Academic Qualifications pilot within the context of the European Large Scale Project STORK2.0.

His main interests are ISMS, Risk Management, Data Protection and Privacy, eAdministration and Technology Surveillance.

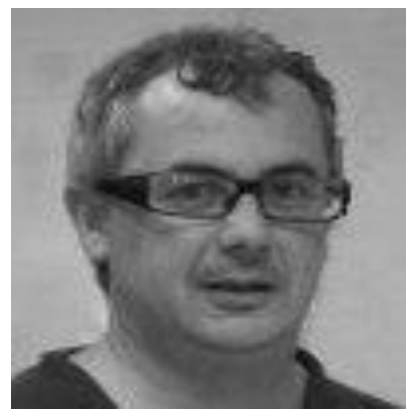

Jose Pascual Gumbau Mezquita is the manager of the Office for Planning and Technology Forecast of the Universitat Jaume I and the Technology Innovation Lab (TecLab). He is an associate professor of the Computer Science and Artificial Intelligence department. He holds a CISA certification from ISACA and coordinates the IT Governance group of the Spanish universities in the context of the TIC sector of the Board of Spanish Rectors.

His main interests are System Design, Innovation, Management and Project Methodologies, Information Systems Audit and IT Governance.

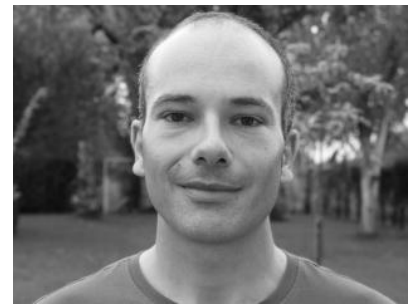

Paúl Santapau works as a Technology Innovation Specialist at the Office for Planning and Technology Forecast of the Universitat Jaume I. He specifically works for the Technology Innovation Lab (TecLab). He has contributed to notable projects like Clauer, CryptoApplet, jXAdES, the adoption of an Information Security Management System (ISMS) and the European Large Scale Projects STORK and STORK2.0. He holds a CISSP certification from ISC2.

His main interests are Software Development, Information Security, Network Security and Project Management.

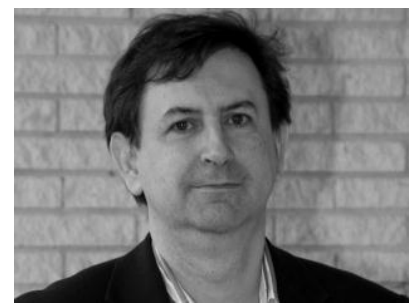

Andrés Marzal Varó graduated in Computer Science and obtained the degree of Doctor in Computer Science from Universitat Politécnica de Valencia. He became a titular lecturer at Universitat Jaume I (UJI) in 1996. He has coordinated several projects related with Information Systems in UJI. The most notable are: the degree information system (LLEU) and the promotion of the Open Knowledge. He has been researching for more than 18 years and teaching for more than 15 . He has published more than 60 publications in journals, books and international congresses and has lead several research projects. He has taken part in several committees within the university bodies. He has also been awarded with the I prize for the Teaching Excellence by the Social Council of UJI. 